\title{
Apoptosis-Inducing Activity of Marine Sponge Haliclona sp. Extracts Collected from Kosrae in Nonsmall Cell Lung Cancer A549 Cells
}

\author{
Woori Bae, ${ }^{1}$ Hyun Kyung Lim, ${ }^{2}$ Kyoung Mee Kim, ${ }^{1,2}$ Hyosun Cho, ${ }^{1,2}$ Sun Yi Lee, ${ }^{1,2}$ \\ Choon-Sik Jeong, ${ }^{1,2}$ Hyi-Seung Lee, ${ }^{3}$ and Joohee Jung ${ }^{1,2}$ \\ ${ }^{1}$ College of Pharmacy, Duksung Women's University, Seoul 132-714, Republic of Korea \\ ${ }^{2}$ Innovative Drug Center, Duksung Women's University, Seoul 132-714, Republic of Korea \\ ${ }^{3}$ Korea Institute of Ocean Science \& Technology, Ansan 426-744, Republic of Korea \\ Correspondence should be addressed to Joohee Jung; joohee@duksung.ac.kr
}

Received 2 April 2015; Revised 7 June 2015; Accepted 10 June 2015

Academic Editor: Helmut Hugel

Copyright (C) 2015 Woori Bae et al. This is an open access article distributed under the Creative Commons Attribution License, which permits unrestricted use, distribution, and reproduction in any medium, provided the original work is properly cited.

Although various anticancer drugs have been developed for the treatment of nonsmall cell lung cancer, chemotherapeutic efficacy is still limited. Natural products such as phytochemicals have been screened as novel alternative materials, but alternative funds such as marine bioresources remain largely untapped. Of these resources, marine sponges have undergone the most scrutiny for their biological activities, including antiinflammatory, antiviral, and anticancer properties. However, the biological mechanisms of the activities of these marine sponges are still unclear. We investigated the anticancer activity of marine sponges collected from Kosrae in Micronesia and examined their mechanisms of action using nonsmall cell lung cancer A549 cells as a model system. Of 20 specimens, the Haliclona sp. (KO1304-328) showed both dose- and time-dependent cytotoxicity. Further, methanol extracts of Haliclona sp. significantly inhibited cell proliferation and cell viability. A549 cells treated with Haliclona sp. demonstrated induced expression of c-Jun N-terminal kinase (JNK), p53, p21, caspase-8, and caspase-3. The percentage of apoptotic cells significantly increased in A549 cultures treated with Haliclona sp. These results indicate that Haliclona sp. induces apoptosis via the JNKp53 pathway and caspase-8, suggesting that this marine sponge is a good resource for the development of drugs for treatment of nonsmall cell lung cancer.

\section{Introduction}

Complementary medicine has been used for the enhancement of chemotherapeutic efficacy and reduction of adverse effects for several years. Specifically, natural products have been utilized and their active compounds developed as novel anticancer drugs. The major bioresources have largely been phytochemicals, but marine bioresources have been the subject of recent study due to their global abundance. In fact, it has been suggested that more than 3,000,000 such organisms could be good candidates for development of novel drugs. The bioactivities of several biomaterials have been reported, but much remains to be studied. For example, active constituents isolated from soft corals were reported to have anti-inflammatory activity $[1,2]$. Additionally, various marine sponges are known to have antibacterial, anti-inflammatory, antiangiogenic, and cytotoxic activities [3-6]. However, the mechanisms of action for these activities are largely unclear. In the present study, we focused on the anticancer effects of marine sponges. In particular, we chose nonsmall cell lung cancer (NSCLC), which has a high mortality due to its resistance to radiation and chemotherapy [7]. Therefore, in an effort to overcome these limitations, we investigated several marine sponge extracts collected from Kosrae, Micronesia, and examined their anticancer activities and mechanisms of action. 


\section{Materials and Methods}

2.1. Specimen Preparation. Sponge specimens (KO1304 series) were collected by hand with scuba equipment at Kosrae Island in the Federated States of Micronesia in April 2013. The specimens were immediately washed with sterilized artificial seawater and lyophilized. These specimens extracted with methanol $(3 \times 3 \mathrm{~L})$ were provided by the Korea Institute of Ocean Science \& Technology. Each specimen was dissolved in sterile distilled water (final concentration of $50 \mathrm{mg} / \mathrm{mL}$ ) as previously described [6]. Aliquots of specimens were stored at $-20^{\circ} \mathrm{C}$ until use.

2.2. Cells and Treatment. Nonsmall cell lung cancer A549 (CCL-185) cells (ATCC, Manassas, VA) were cultured in Ham's F-12 medium (Gibco, Grand Island, NY) supplemented with $10 \%$ fetal bovine serum (GenDEPOT, Barker, TX) and $1 \%$ penicillin/streptomycin (GenDEPOT) in a humidified $5 \%$ $\mathrm{CO}_{2}$ incubator. Cells in the exponential growth phase were used. The samples were added to the medium and treated with extract for $24 \mathrm{~h}$ or $48 \mathrm{~h}$.

2.3. Cell Cytotoxicity. Cell cytotoxicity was determined using the Cell Counting Kit-8 (CCK-8, DOJINDO, Japan). Briefly, cells $\left(3 \times 10^{3}\right.$ cells/well $)$ were seeded in 96-well plates and incubated for $24 \mathrm{~h}$. After treatment with samples for $24 \mathrm{~h}$ or $48 \mathrm{~h}, \mathrm{CCK}-8$ reagent $(10 \mu \mathrm{L})$ was added to each well and incubated for $3 \mathrm{~h}$ at $37^{\circ} \mathrm{C}$. Absorbance at $450 \mathrm{~nm}$ was measured using a microplate reader (Infinite M200 PRO, TECAN, Austria).

2.4. Cellular Morphology. Cells $\left(3 \times 10^{3}\right.$ cells/well $)$ were seeded in 96-well plates and incubated for $24 \mathrm{~h}$. Cells were treated with extract for $24 \mathrm{~h}$ or $48 \mathrm{~h}$ and observed under light microscopy (40x magnification) (Nikon Eclipse TS100, Japan).

2.5. Clonogenic Assay. Cells were seeded in six-well plates at a density of 100-500 cells/well. After $24 \mathrm{~h}$, cells were treated with extract and incubated until colony formation. Colonies consisting of at least 50 cells were fixed and stained with crystal violet $(0.5 \% \mathrm{w} / \mathrm{v})$ in $10 \%$ methanol and counted. Plate efficiency (PE) and survival fraction (SF) were calculated using the following [8]:

$$
\begin{aligned}
& \mathrm{PE}=\left(\frac{\text { Number of colonies counted }}{\text { Number of cells plated }}\right) \times 100, \\
& \mathrm{SF}=\left(\frac{\text { PE of treated sample }}{\text { PE of control }}\right) \times 100 .
\end{aligned}
$$

2.6. Western Blot Analysis. Cells were seeded in a six-well plate at a density of 4-6 $610^{4}$ cells/well and allowed to incubate for $24 \mathrm{~h}$. Extract was added to each well and incubated for $48 \mathrm{~h}$. Cells were harvested and lysed in RIPA buffer (GenDEPOT) with protease inhibitors (Xpert protease inhibitor cocktail solution, GenDEPOT) and phosphatase inhibitors (Xpert phosphatase inhibitor cocktail solution, GenDEPOT).
TABLE 1: Cytotoxicity of KO1304 series in A549 cells.

\begin{tabular}{lccc}
\hline Sample name & $\mathrm{IC}_{30}(\mu \mathrm{g} / \mathrm{mL})$ & Sample name & $\mathrm{IC}_{30}(\mu \mathrm{g} / \mathrm{mL})$ \\
\hline KO1304-101 & $>100$ & KO1304-207 & $>100$ \\
KO1304-102 & $>100$ & KO1304-208 & $>100$ \\
KO1304-103 & $>100$ & KO1304-221 & $>100$ \\
KO1304-105 & $>100$ & KO1304-223 & $>100$ \\
KO1304-107 & $>100$ & KO1304-301 & $>100$ \\
KO1304-201 & $>100$ & KO1304-302 & $>100$ \\
KO1304-203 & $>100$ & KO1304-303 & $>100$ \\
KO1304-204 & $>100$ & KO1304-326 & $>100$ \\
KO1304-205 & $>100$ & KO1304-328 & $68.3 \pm 0.4$ \\
KO1304-206 & $>100$ & KO1304-329 & $>100$ \\
\hline
\end{tabular}

Each extract (titrated from 6.25 to $100 \mu \mathrm{g} / \mathrm{mL}$ ) was added to A549 cells for $48 \mathrm{~h} . \mathrm{IC}_{30}$ is the concentration at which $30 \%$ inhibition of cell viability is achieved.

Cell lysates were boiled in 5x sample buffer and separated by $10 \%$ SDS-PAGE. Proteins were transferred onto PVDF membranes (Millipore) using a semidry electroblotter (Peqlab, Germany). Membranes were blocked with 5\% skim milk in TBS-T (50 mM Tris-HCl pH 7.4, 150 mM NaCl, 0.1\% Tween 20) and sequentially incubated overnight with primary antibodies at $4^{\circ} \mathrm{C}$. Membranes underwent additional incubation at room temperature and were then probed with secondary antibody. Immunoreactive proteins were visualized using ECL reagents and developed with X-ray film. Antibodies and dilutions are as follows: p53, p21 (1:2000, Millipore), c-Jun N-terminal kinase (JNK, 1:500, Santa Cruz Biotechnology), Bax (1:1000, Cell Signaling), caspase-3, caspase-8, caspase9 (1:1000, Cell Signaling), $\beta$-actin (1:5000, Sigma-Aldrich), anti-mouse $\operatorname{IgG}(\mathrm{H}+\mathrm{L})$ horseradish peroxidase conjugate, and anti-rabbit $\operatorname{IgG}(\mathrm{H}+\mathrm{L})$ horseradish peroxidase conjugate (1:3000, Bio-Rad).

2.7. Cell Cycle. Cells were seeded in a $60-\mathrm{mm}$ plate and treated with extract $(25 \mu \mathrm{g} / \mathrm{mL}$ or $50 \mu \mathrm{g} / \mathrm{mL})$ for $1 \mathrm{~h}, 2 \mathrm{~h}, 4 \mathrm{~h}, 8 \mathrm{~h}$, $12 \mathrm{~h}$, or $24 \mathrm{~h}$. Incubated cells were collected and fixed with $70 \%$ ethanol. Fixed cells were washed with PBS and stained with propidium iodide (PI) staining solution. Cell cycle was detected using a BD FACSCanto II system (BD biosciences, San Jose, CA, USA).

2.8. Apoptosis. Cells were seeded in a six-well plate and treated with extract for $24 \mathrm{~h}$ or $48 \mathrm{~h}$. Incubated cells were stained with Annexin V-FLUOS staining kit (Roche, Mannheim, Germany). Apoptosis was detected using a Guava easyCyte flow cytometer (Merck Millipore, Darmstadt, Germany).

\section{Results and Discussion}

3.1. Screening Test of KO1304 Series. The cytotoxicity of 20 sponge specimens (KO1304 series) was determined in order to determine their use as an anticancer drug candidate resource. Each specimen was serially diluted and applied to A549 cells for $48 \mathrm{~h}$. As shown in Table 1, despite the inactivity of the other specimens, KO1304-328 inhibited cell viability 


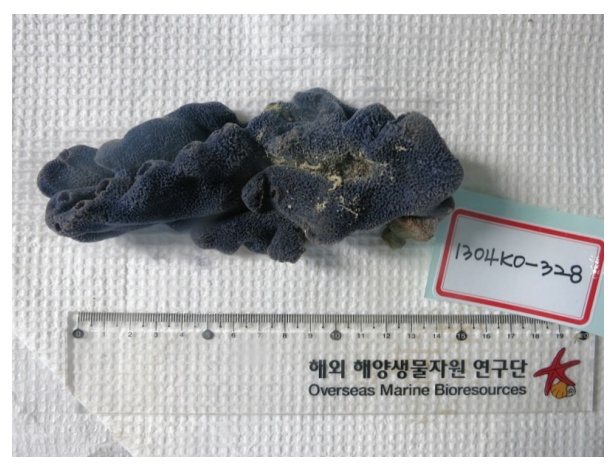

Figure 1: Morphology of Haliclona sp.

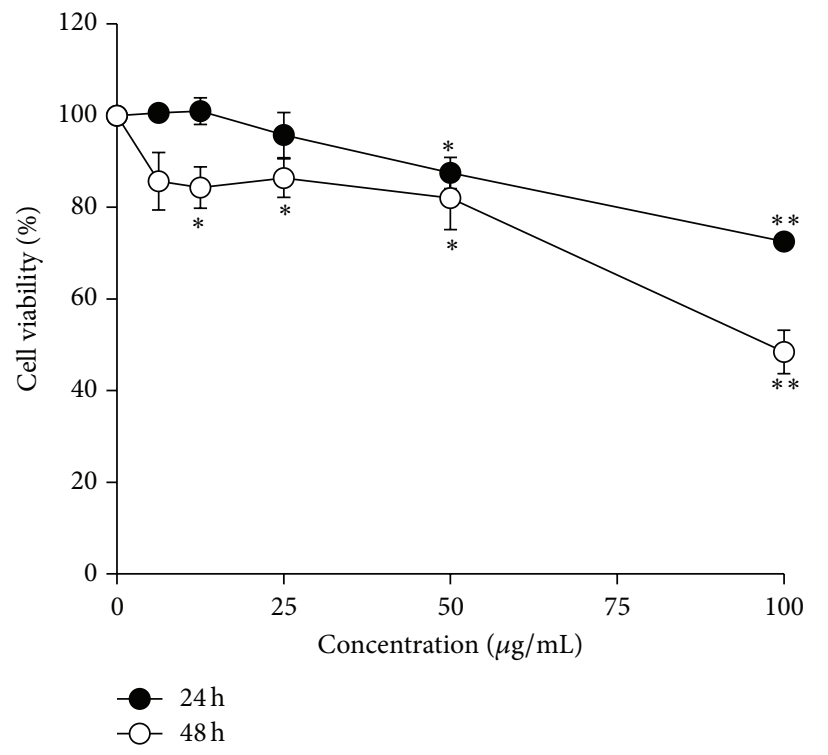

(a)
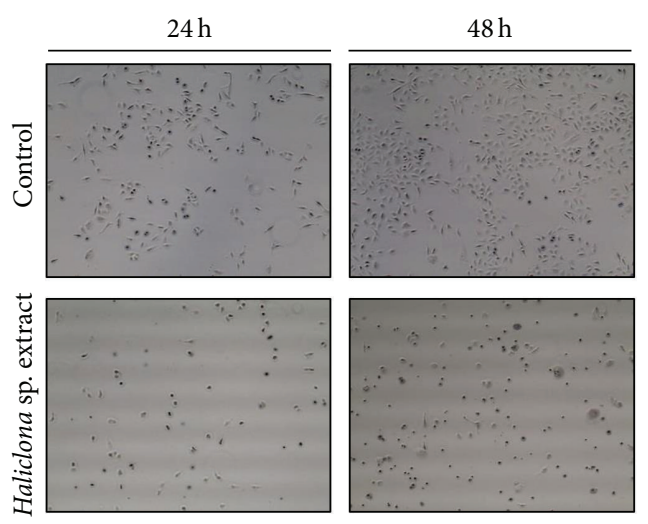

FIGURE 2: Haliclona sp. extract inhibits cell viability in A549 cells. (a) A549 cells were treated with Haliclona sp. extract for $24 \mathrm{~h}$ or $48 \mathrm{~h}$. (b) Haliclona sp. extract $(100 \mu \mathrm{g} / \mathrm{mL})$ was added to the medium. Cells were observed by microscopy (40x magnifications).

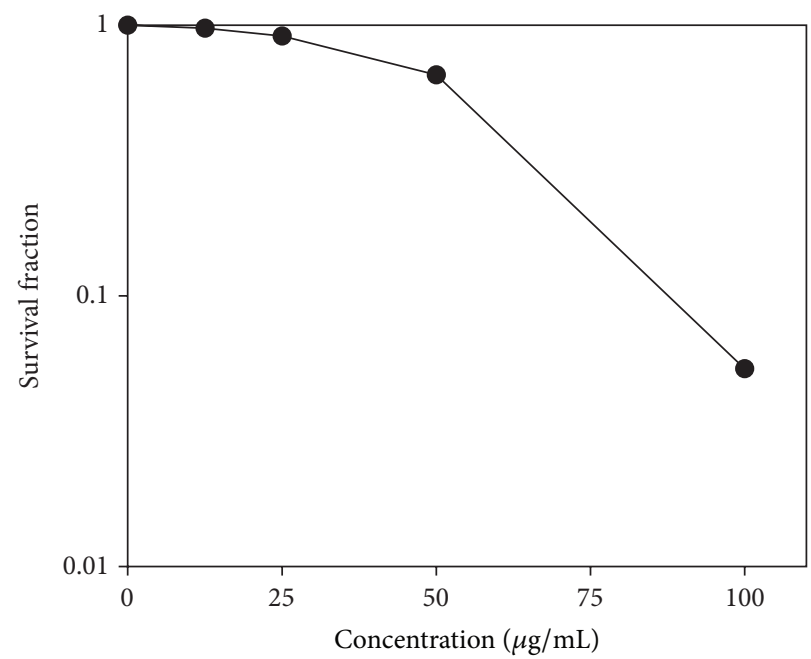

FIGURE 3: Haliclona sp. extract inhibits colony formation in A549 cells. A549 cells were treated with Haliclona sp. extract and incubated until the formation of colonies. After two weeks, colonies were counted, and the survival ratio was calculated as described in Section 2. 

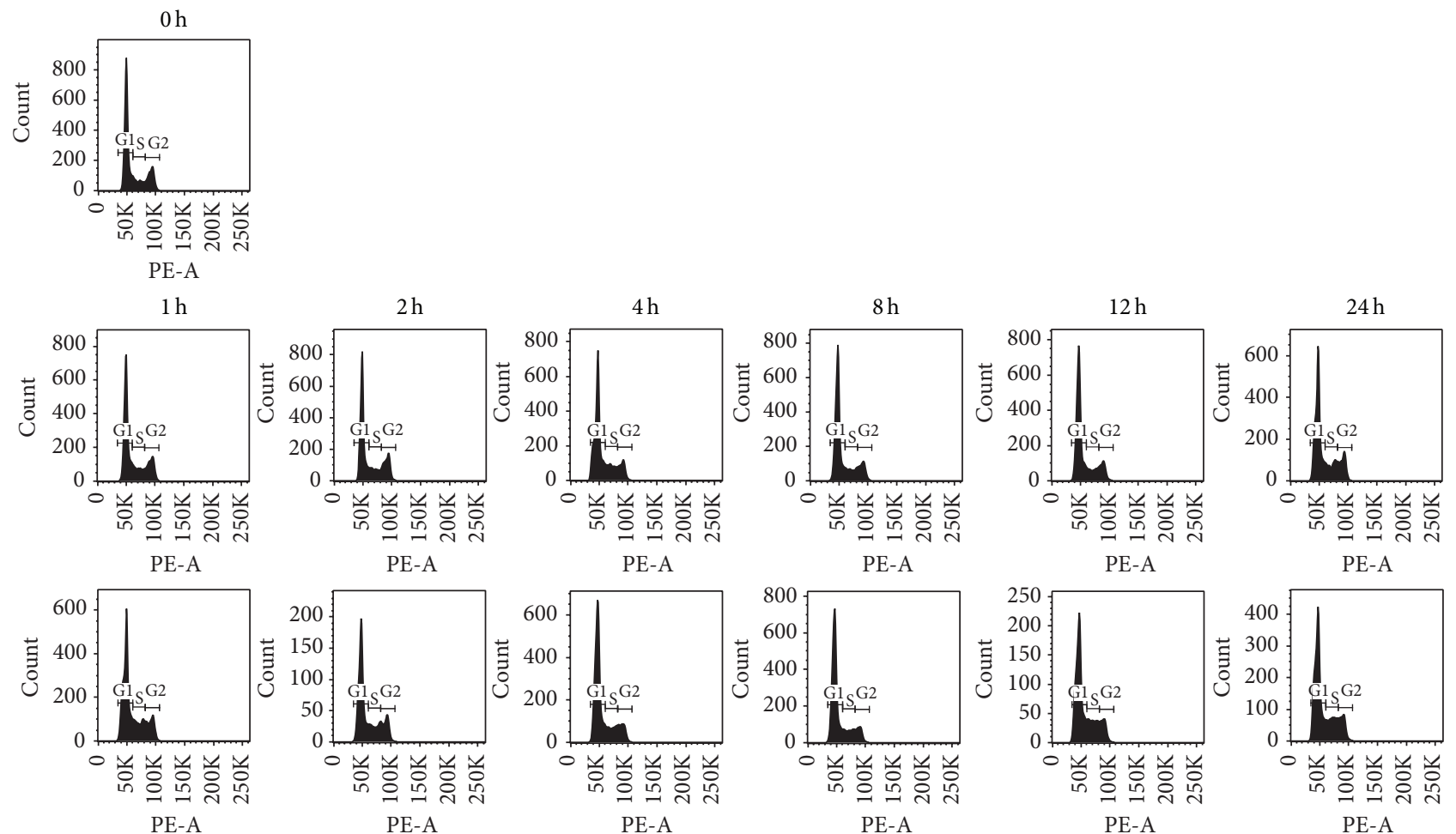

(a)
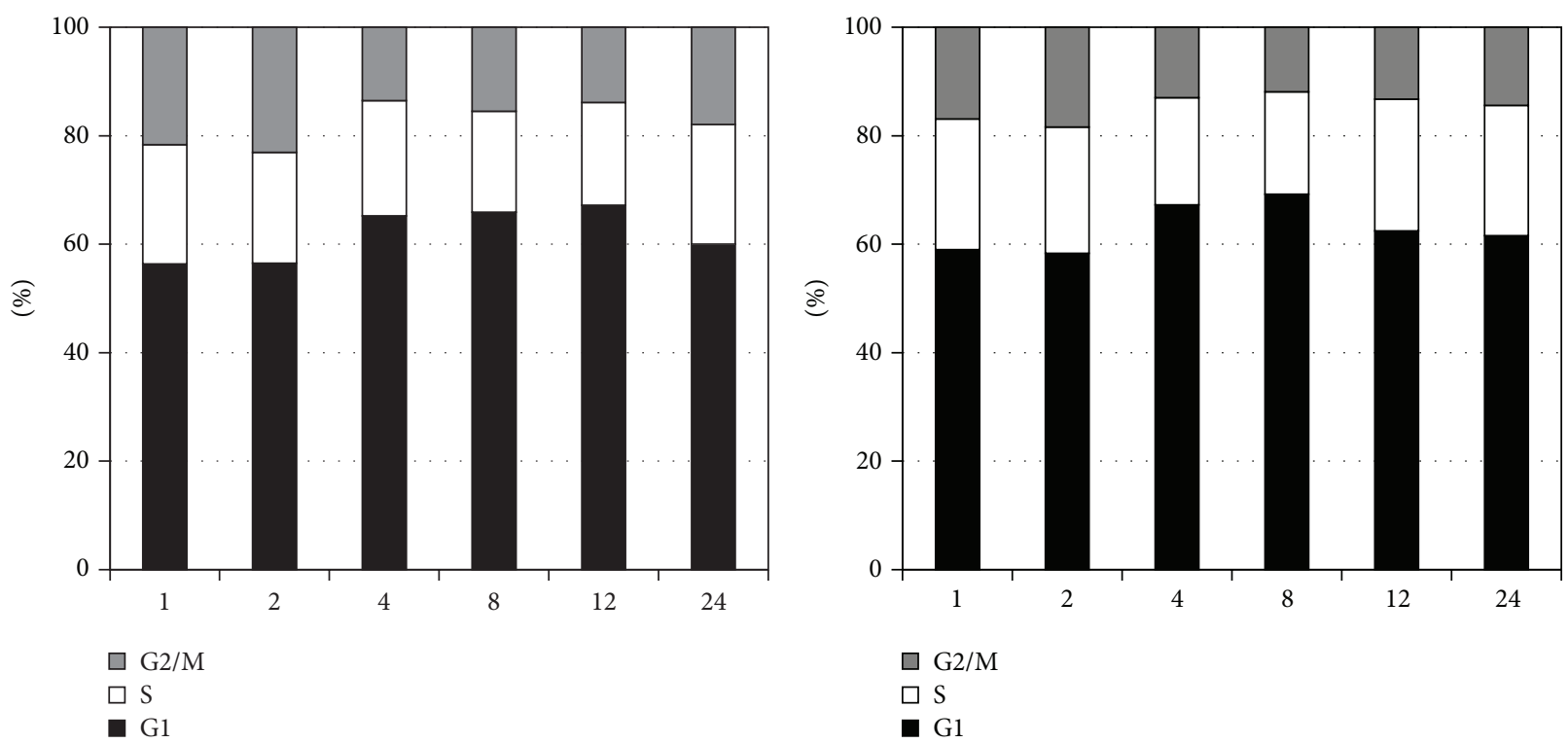

(b)

(c)

Figure 4: Haliclona sp. extract induced cell cycle arrest in A549 cells. (a) DNA histograms of A549 cells treated with Haliclona sp. extract (upper, $25 \mu \mathrm{g} / \mathrm{mL}$; lower, $50 \mu \mathrm{g} / \mathrm{mL}$ ). The cell cycle distribution of A549 treated with Haliclona sp. extract $(25 \mu \mathrm{g} / \mathrm{mL}$ (b) and $50 \mu \mathrm{g} / \mathrm{mL}$ (c)) was analyzed by flow cytometry.

by more than $30 \%$. KO1304-328 was identified as Haliclona sp. (Figure 1), which has been reported to have cytotoxic [9], antibacterial [10, 11], antifungal [11], and anticancer effects in breast, prostate, and colon cancer cells $[9,12]$. Papuamine and haliclonadiamine isolated from Haliclona sp. were reported as active components [12]. However, the anticancer mechanism of Haliclona sp. is unclear, particularly that against human nonsmall cell lung cancer. Haliclona sp. extract is widely described in complementary medicine, although the bioactive constituents of Haliclona sp. had not been yet isolated 


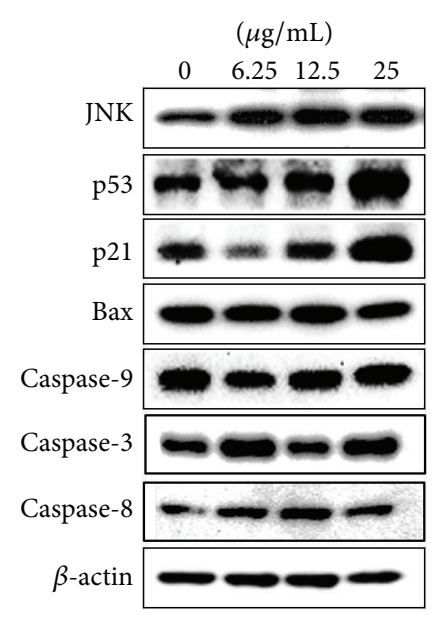

(a)

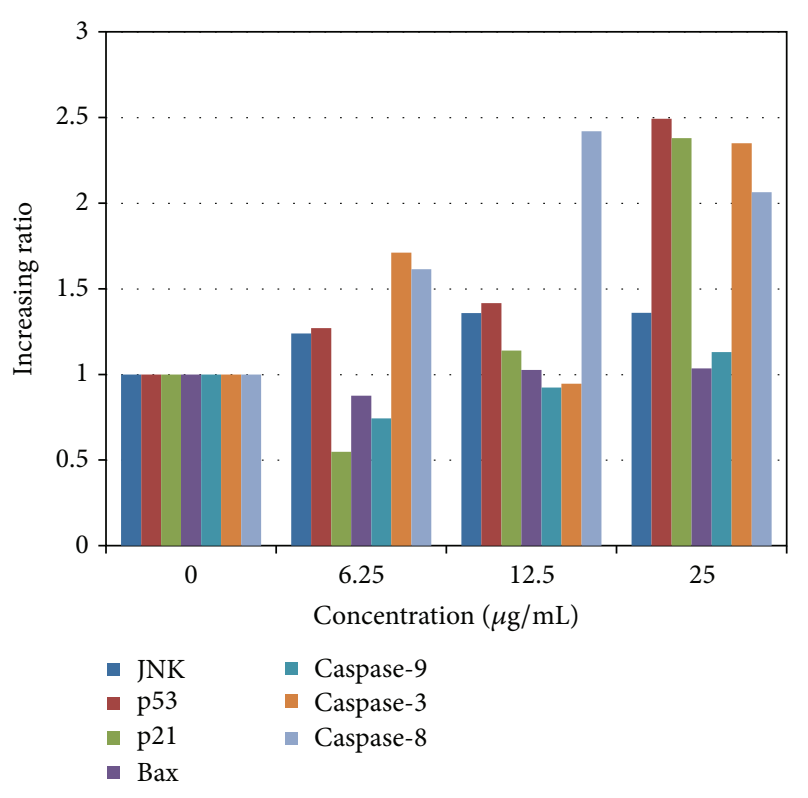

(b)

FIGURE 5: Haliclona sp. extract induces the expression of proteins related to the JNK and extrinsic apoptotic pathway. A549 cells were treated with Haliclona sp. extract for $48 \mathrm{~h}$. (a) Protein levels were determined using Western blotting. (b) Protein bands were analyzed by ImageJ software. The data were calculated by the ratio of each to $\beta$-actin bands (as corresponding bands).

and evaluated. Therefore, the mechanism of the anticancer activity of Haliclona sp. extract was investigated in human nonsmall cell lung cancer A549 cells.

\subsection{Haliclona sp. Suppresses Cell Viability and Cell Prolifera-} tion. To evaluate cytotoxicity, Haliclona sp. extract was serially diluted and applied to A549 cells for $24 \mathrm{~h}$ or $48 \mathrm{~h}$. As shown in Figure 2(a), cell viability of A549 cells decreased in a dose- and time-dependent fashion. At $24 \mathrm{~h}$, cytotoxicity was statistically significant for extracts of 50 and $100 \mu \mathrm{g} / \mathrm{mL}$, but maximal cell viability inhibition was only $27.5 \pm 2 \%$. In A549 cells treated with Haliclona sp. extract for $48 \mathrm{~h}$, a significant difference in cell viability was shown at 12.5, 25, 50, and $100 \mu \mathrm{g} / \mathrm{mL}$ (Figure 2(a)). Further, the maximum dose $(100 \mu \mathrm{g} / \mathrm{mL})$ inhibited cell viability by $51.6 \pm 4.7 \%$. Concurrently, we treated A549 cells with a control or Haliclona sp. extract and observed the decrease of cell density at 24 or $48 \mathrm{~h}$ (Figure 2(b)). Furthermore, the cytotoxicity of Haliclona sp. extract showed only in A549 cells, but not in RAW264.7 cells as noncancerous cell line (see Supplemental Data 1 in the Supplementary Material available online at http://dx.doi.org/ $10.1155 / 2015 / 717959)$. This data suggests that Haliclona sp. extract exerts an anticancer effect in a dose- and time-dependent manner.

We also investigated the effect of Haliclona sp. extract on cell proliferation. Single, untreated A549 cells proliferated and formed colonies, but those cells treated with Haliclona sp. extract were suppressed in colony formation ability
(Figure 3). This result indicates that Haliclona sp. extract dose-dependently inhibits cell proliferation.

Inhibition of cell proliferation was commonly induced by the cell cycle arrest $[13,14]$. Radiation is well known for inducing the permanent G1 arrest and suppressing the cell proliferation [13]. So, we investigated if Haliclona sp. extracts affected the cell cycle as radiation. For analysis of cell cycle, A549 cells treated with Haliclona sp. extracts were stained with PI solution and detected the phases of the cycle (Figure 4). Haliclona sp. showed slight and temporary G1 phase arrest (Figures 4(b) and $4(\mathrm{c})$ ). The results suggested that Haliclona sp. could delay the cell proliferation.

\subsection{Haliclona sp. Induces Apoptosis via the JNK and Extrinsic} Pathway. To investigate the cellular mechanism of Haliclona sp. extract, protein levels were analyzed using Western blots. Specifically, we examined the apoptosis-inducing factors of JNK, p53, Bax, caspase-3, caspase-8, and caspase-9 which activate the mitochondrial or intrinsic apoptotic pathway [15]. JNK phosphorylates and regulates the activity of p53 and its stability [16-18]. The p53 tumor suppressor gene plays an important role in cell cycle, DNA repair, replicative senescence, and cell death [19]. As shown in Figure 5, A549 cells treated with Haliclona sp. extracts displayed significantly increased levels of JNK and p53 proteins, as well as p21 a downstream gene upregulated by $\mathrm{p} 53$. In several studies, the JNKp53 pathway was also reported as one of the apoptotic pathways induced by natural products $[16,20]$. However, levels of 

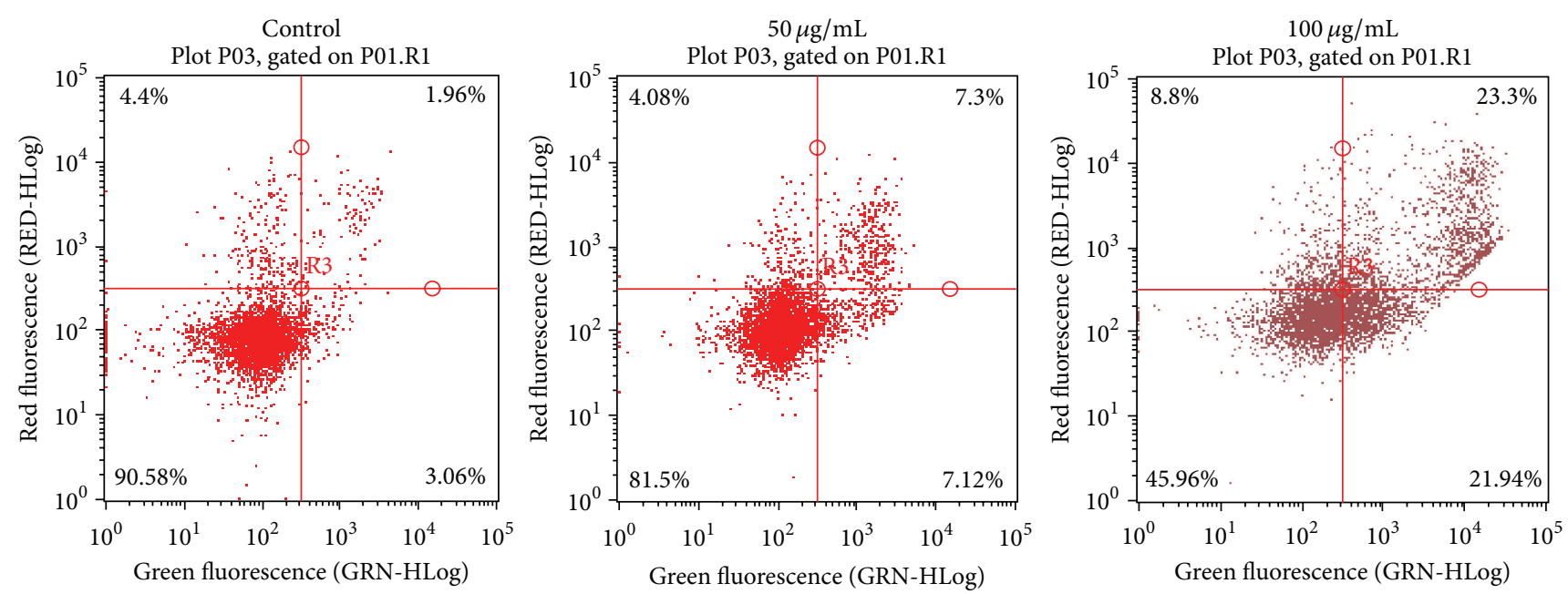

(a)

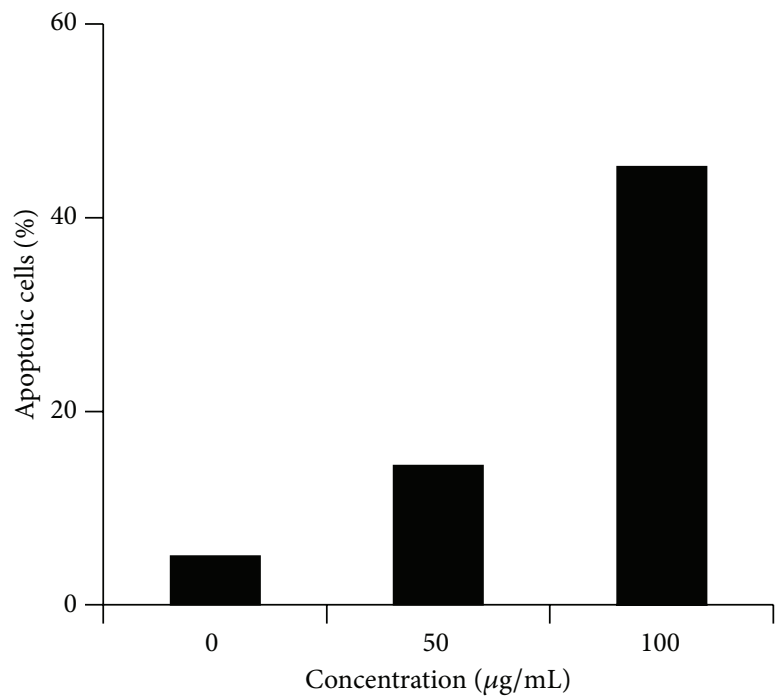

(b)

Figure 6: Haliclona sp. extract increased apoptosis. A549 cells were treated with Haliclona sp. extract for 48 h. Apoptotic cells were determined by Annexin V and PI staining and analyzed as described in Section 2. (a) Upper left, necrosis (\%); upper right, late apoptosis (\%); lower left, viable (\%); lower right: early apoptosis (\%). (b) The data showed total apoptosis (early apoptosis and late apoptosis).

markers of the intrinsic apoptosis pathway, Bax and caspase9, were not changed by Haliclona sp. extracts. Interestingly, the markers of extrinsic apoptosis pathway, caspase- 8 and caspase- 3 , were increased by Haliclona sp. extracts. The results suggest that Haliclona sp. extracts activate JNK and caspase-8, thereby activating the apoptotic pathway and inhibiting cell viability and proliferation. Still, Haliclona sp. extract remained to be determined regarding the upper stream of JNK and caspase-8. Several studies reported the relationship between JNK and caspase-8 induced apoptosis [21-23]. TRAIL death receptor activates caspase- 8 and also JNK [21-23]. It may influence the anticancer effect of Haliclona sp. extract.

To verify the induction of apoptosis, cells treated with Haliclona sp. extract were stained with Annexin V and PI. As shown in Figure 6, the percentage of apoptotic cells increased in a dose-dependent manner, suggesting that Haliclona sp. extracts have apoptosis-inducing activity via the JNK and extrinsic apoptotic pathway.

\section{Conclusions}

In this study, we examined the chemotherapeutic effects of marine sponges against A549 nonsmall cell lung cancer cells. We found that a single isolate, Haliclona sp., had significant anticancer activity and investigated its mechanism. Our results indicate that Haliclona sp. extracts suppress cell viability and proliferation. Eventually, Haliclona sp. extract could induce apoptosis via activation of JNK and caspase-8 (Figure 7). Thus, the apoptosis-inducing activity of Haliclona sp. extract could be utilized for future development of chemotherapeutic drugs against nonsmall cell lung cancer. 


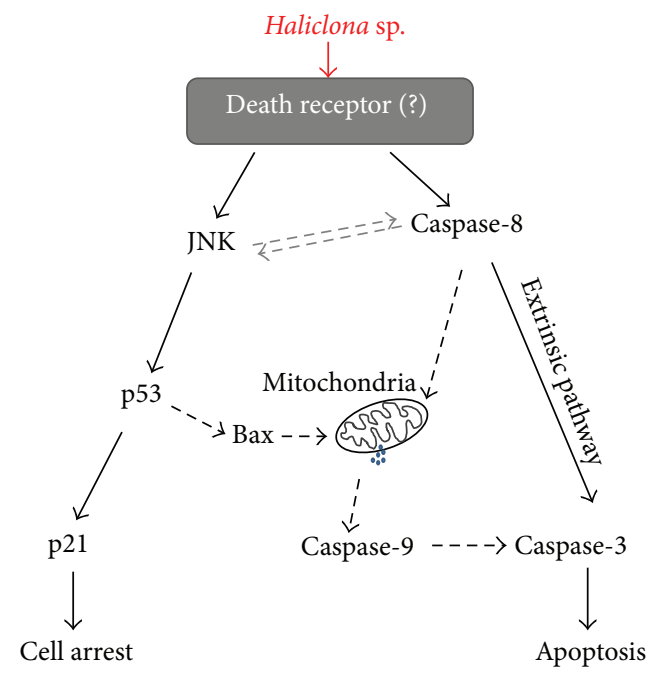

Figure 7: Molecular mechanism of anticancer action induced by Haliclona sp. extract.

\section{Conflict of Interests}

The authors declare that there is no conflict of interests regarding the publication of this paper.

\section{Authors' Contribution}

Woori Bae and Hyun Kyung Lim contributed equally to this paper.

\section{Acknowledgments}

This study was supported by the Ministry of Oceans and Fisheries (PM57561) and NRF (2014R1A1A3049498), Korea.

\section{References}

[1] E. Reina, F. A. Ramos, L. Castellanos, M. Aragõn, and L. F. Ospina, "Anti-inflammatory $R$-prostaglandins from caribbean colombian soft coral Plexaura homomalla," Journal of Pharmacy and Pharmacology, vol. 65, no. 11, pp. 1643-1652, 2013.

[2] W.-C. Wei, P.-J. Sung, C.-Y. Duh, B.-W. Chen, J.-H. Sheu, and N.-S. Yang, "Anti-inflammatory activities of natural products isolated from soft corals of Taiwan between 2008 and 2012," Marine Drugs, vol. 11, no. 10, pp. 4083-4126, 2013.

[3] A. Randazzo, G. Bifulco, C. Giannini et al., "Halipeptins A and B: two novel potent anti-inflammatory cyclic depsipeptides from the Vanuatu marine sponge Haliclona species," Journal of the American Chemical Society, vol. 123, no. 44, pp. 10870-10876, 2001.

[4] K. L. Erickson, J. A. Beutler, J. H. Cardellina II, and M. R. Boyd, "Salicylihalamides A and B, novel cytotoxic macrolides from the marine sponge Haliclona sp." Journal of Organic Chemistry, vol. 62, no. 23, pp. 8188-8192, 1997.

[5] K. Senthilkumar, J. Venkatesan, P. Manivasagan, and S.-K. Kim, "Antiangiogenic effects of marine sponge derived compounds on cancer," Environmental Toxicology and Pharmacology, vol. 36, no. 3, pp. 1097-1108, 2013.
[6] H. K. Lim, W. Bae, H. S. Lee, and J. Jung, "Anticancer activity of marine sponge Hyrtios sp. extract in human colorectal carcinoma RKO cells with different p53 status," BioMed Research International, vol. 2014, Article ID 413575, 5 pages, 2014.

[7] E. E. Graves, A. Maity, and Q.-T. Le, "The tumor microenvironment in non-small-cell lung cancer," Seminars in Radiation Oncology, vol. 20, no. 3, pp. 156-163, 2010.

[8] J. Jung, S.-J. Park, H. K. Chung et al., "Polymeric nanoparticles containing taxanes enhance chemoradiotherapeutic efficacy in non-small cell lung cancer," International Journal of Radiation Oncology Biology Physics, vol. 84, no. 1, pp. e77-e83, 2012.

[9] W. M. Alarif, A. Abdel-Lateff, S. S. Al-Lihaibi, S.-E. N. Ayyad, and F. A. Badria, "A new cytotoxic brominated acetylenic hydrocarbon from the marine sponge haliclona sp. with a selective effect against human breast cancer," Zeitschrift für Naturforschung C, vol. 68, no. 1-2, pp. 70-75, 2013.

[10] A. Hoppers, J. Stoudenmire, S. Wu, and N. B. Lopanik, "Antibiotic activity and microbial community of the temperate sponge, Haliclona sp.", Journal of Applied Microbiology, vol. 118, no. 2, pp. 419-430, 2015.

[11] M. Nazemi, M. A. Salimi, P. A. Salimi, A. Motallebi, S. T. Jahromi, and O. Ahmadzadeh, "Antifungal and antibacterial activity of Haliclona sp. from the Persian Gulf, Iran," Journal de Mycologie Médicale, vol. 24, no. 3, pp. 220-224, 2014.

[12] H. Yamazaki, D. S. Wewengkang, S.-I. Kanno et al., "Papuamine and haliclonadiamine, obtained from an Indonesian sponge Haliclona sp., inhibited cell proliferation of human cancer cell lines," Natural Product Research, vol. 27, no. 11, pp. 1012-1015, 2013.

[13] M. Kriegs, K. Gurtner, Y. Can et al., "Radiosensitization of NSCLC cells by EGFR inhibition is the result of an enhanced p53-dependent G1 arrest," Radiotherapy and Oncology, vol. 115, no. 1, pp. 120-127, 2015.

[14] Y. Yang, Y. Zhao, X. Ai, B. Cheng, and S. Lu, "Formononetin suppresses the proliferation of human non-small cell lung cancer through induction of cell cycle arrest and apoptosis," International Journal of Clinical and Experimental Pathology, vol. 7, no. 12, pp. 8453-8461, 2014. 
[15] A. R. M. R. Amin, O. Kucuk, F. R. Khuri, and D. M. Shin, "Perspectives for cancer prevention with natural compounds," Journal of Clinical Oncology, vol. 27, no. 16, pp. 2712-2725, 2009.

[16] F. J. Reyes-Zurita, G. Pachón-Peña, D. Lizárraga, E. E. RufinoPalomares, M. Cascante, and J. A. Lupiáñez, "The natural triterpene maslinic acid induces apoptosis in HT29 colon cancer cells by a JNK-p53-dependent mechanism," BMC Cancer, vol. 11, article 154, 2011.

[17] S. Y. Fuchs, V. Adler, T. Buschmann et al., "JNK targets p53 ubiquitination and degradation in nonstressed cells," Genes and Development, vol. 12, no. 17, pp. 2658-2663, 1998.

[18] S. Y. Fuchs, V. Adler, M. R. Pincus, and Z. Ronai, "MEKK1/JNK signaling stabilizes and activates p53," Proceedings of the National Academy of Sciences of the United States of America, vol. 95, no. 18, pp. 10541-10546, 1998.

[19] A. J. Levine, "p53, the cellular gatekeeper for growth and division," Cell, vol. 88, no. 3, pp. 323-331, 1997.

[20] C. M. Viau, D. J. Moura, V. A. Facundo, and J. Saffi, “The natural triterpene $3 \beta, 6 \beta, 16 \beta$-trihydroxy-lup-20(29)-ene obtained from the flowers of Combretum leprosum induces apoptosis in MCF7 breast cancer cells," BMC Complementary \& Alternative Medicine, vol. 14, no. 1, article 280, 2014.

[21] R. Tiwary, W. Yu, J. Li, S.-K. Park, B. G. Sanders, and K. Kline, "Role of endoplasmic reticulum stress in $\alpha$-tea mediated TRAIL/DR5 death receptor dependent apoptosis," PLoS ONE, vol. 5, no. 7, Article ID el1865, 10 pages, 2010.

[22] H. Wajant, K. Pfizenmaier, and P. Scheurich, "Tumor necrosis factor signaling," Cell Death and Differentiation, vol. 10, no. 1 , pp. 45-65, 2003.

[23] T. Hideshima, C. Mitsiades, M. Akiyama et al., "Molecular mechanisms mediating antimyeloma activity of proteasome inhibitor PS-341," Blood, vol. 101, no. 4, pp. 1530-1534, 2003. 


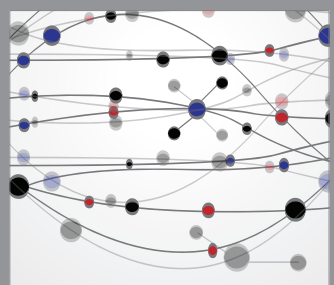

The Scientific World Journal
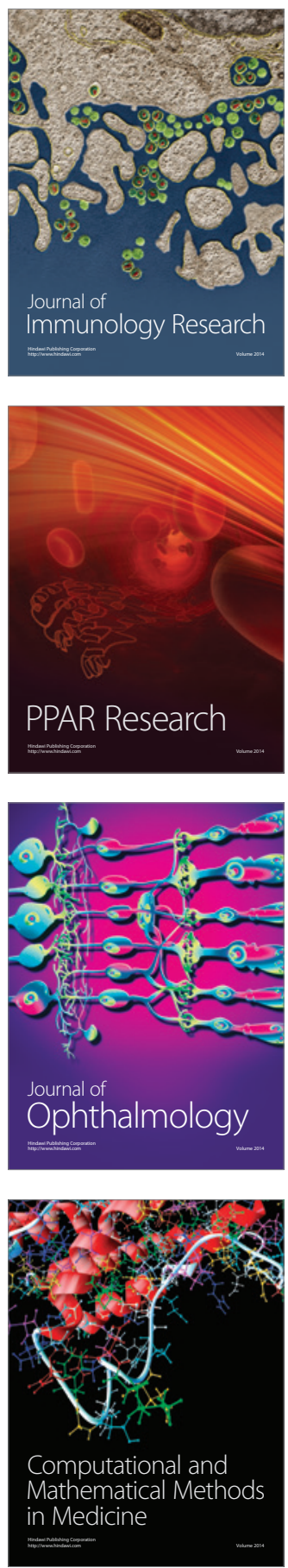

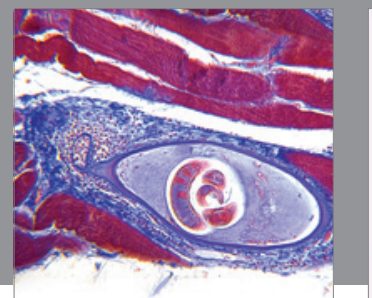

Gastroenterology

Research and Practice
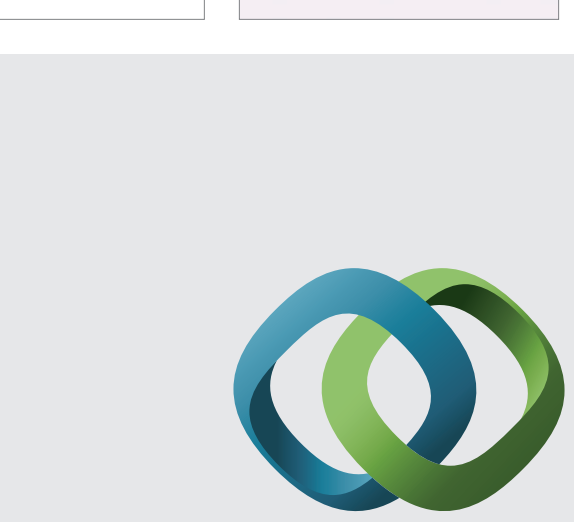

\section{Hindawi}

Submit your manuscripts at

http://www.hindawi.com
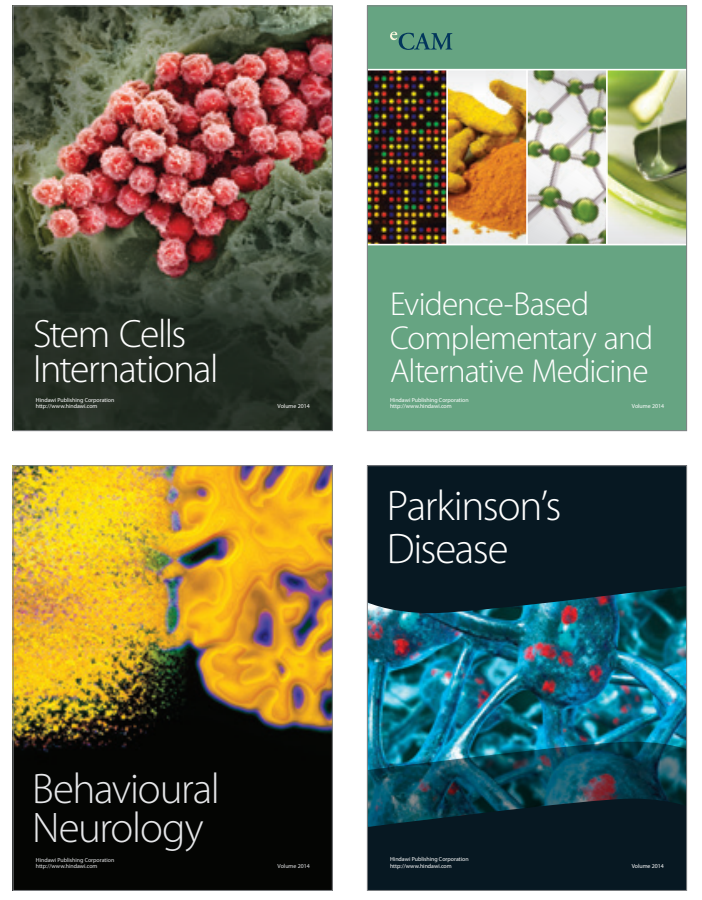
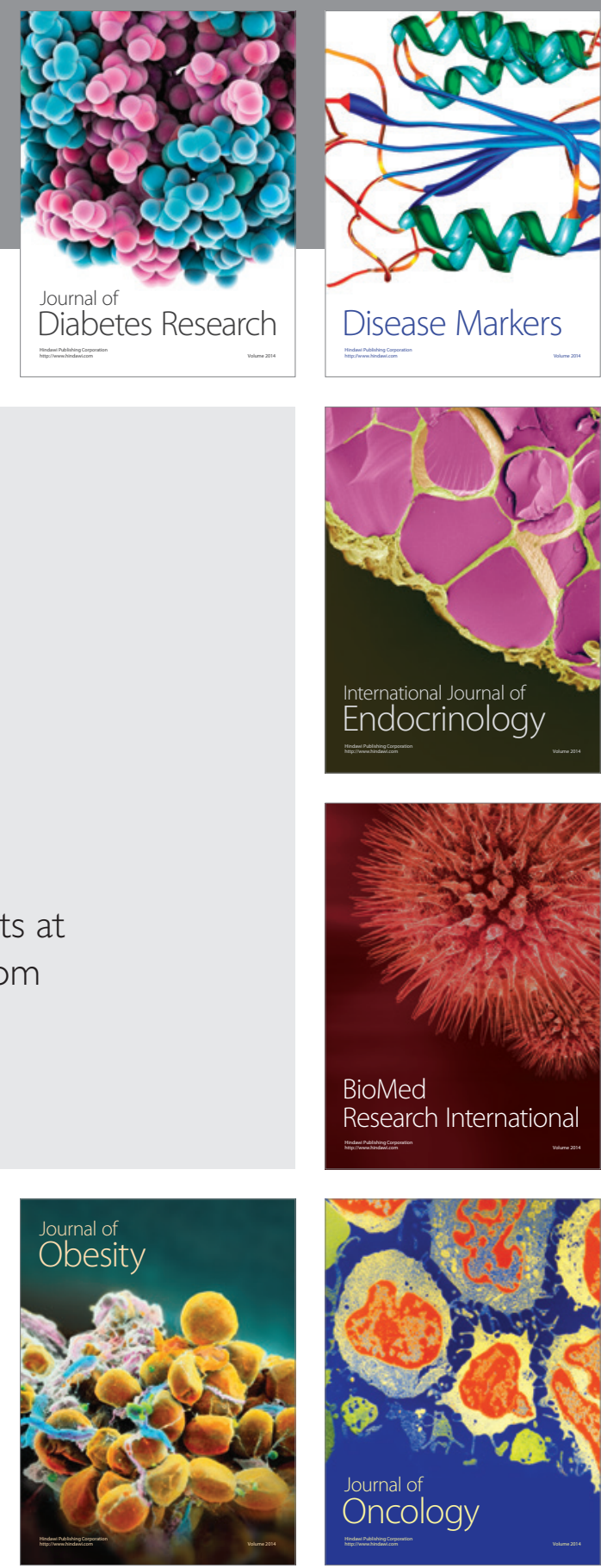

Disease Markers
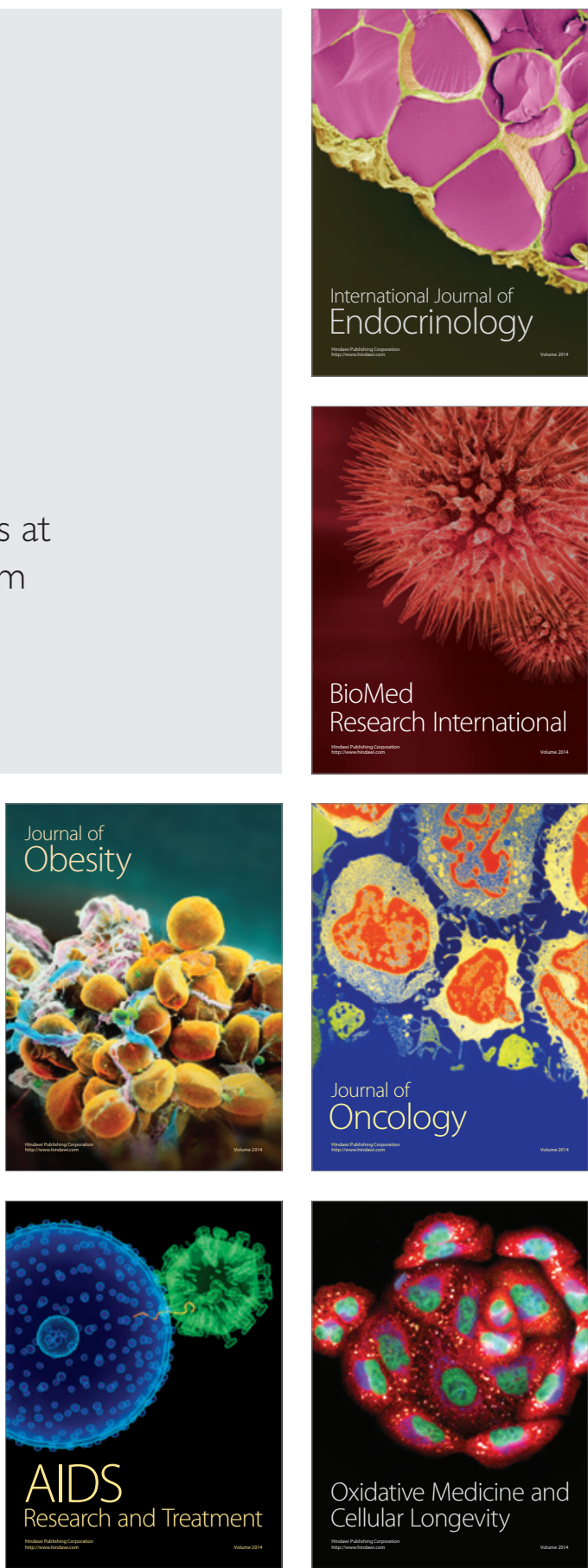